\title{
Compatibility of Streptomyces sp., Metarhizium anisopliae, and Neem Seed Powder against Pigeon Pea Pod Borer Complex
}

\author{
S.V. Agale ${ }^{1,2 *}$, S. Gopalakrishnan ${ }^{2}$, Rajeev Gupta ${ }^{1}$, G.V. Rangarao², \\ V. Srinivas ${ }^{2}$ and S.P. Wani ${ }^{2}$ \\ ${ }^{1}$ Department of Entomology, Indira Gandhi Krishi Vishwavidyalaya, Raipur, 492012, \\ Chhattisgarh, India \\ ${ }^{2}$ International Crops Research Institute for the semi-arid tropics (ICRISAT), \\ Patancheru-502324, Hyderabad, Telangana, India
}

*Corresponding author

A B S T R A C T

\begin{tabular}{|l|}
\hline K e y w o r d s \\
Pigeon pea, Pod borer, \\
$\begin{array}{l}\text { Biopesticides, } \\
\text { Streptomyces sp. SAI- } \\
\text { 25, Metarhizium } \\
\text { anisopliae, Neem seed } \\
\text { powder }\end{array}$ \\
\hline Article Info \\
\hline $\begin{array}{l}\text { Accepted: } \\
\text { 04 January } 2018 \\
\text { Available Online: } \\
\text { 10 February } 2018\end{array}$ \\
\hline
\end{tabular}

\section{Introduction}

Pigeonpea, (Cajanus cajan L.) is the second most important grain legume crop after chickpea that occupies $2^{\text {nd }}$ largest area among the various pulse crops grown in India. It is a staple diet and consumed as green peas as well as dry seeds (Tabo et al., 1995). Globally, the area and production of pigeonpea has increased from 4.43 million hectares (mha) and 3.16 million tonnes (mt) in 2002 to 5.32 $\mathrm{mha}$ and $4.32 \mathrm{mt}$ in 2012, respectively
(FAOSTAT 2012). India is the largest producer and also the largest consumer of pigeonpea in the world. The yield levels of this crop are not very encouraging. Among the factors responsible for low yield, the damage caused by insect pests is one of the major factors in pigeonpea. It is attacked by several insect pests from seedling stage till harvesting. More than 250 insect pests are known to attack pigeonpea (Sharma et al., 2008). However, Balikai and Yelshetty (2008) reported a total of 30 insect pests feeding on 
pigeonpea. Out of these, one pest Helicoverpa armigera (Hubner) was recorded as major pest on this crop causing more than 51 percent damage, whereas, nine other insects viz., Megalurothrips usitatus (Bangall), Empoasca kerri (Pruthi), Clavigralla gibbosa (Spinola), Riptortus pedestris (Fb)., Exelastis atomosa (May.), Melanagromyza obtuse (Mlloch), Cydia ptychora (Meyr.), Maruca testulalis (Geyer) and Etiella zinckenella (Treit)., were recorded as moderate pests inflicting damage between 31 to 50 percent. As many as ten insect pests were recorded as minor pests on this crop, while ten were recorded as low important. Entomopathogenic fungi are often reported to cause high levels of epizootics in nature and environmentally safe. An attractive feature of these fungi is that the virulence caused by contact and the action is through penetration. These fungi are a heterogeneous group of over 100 genera with approximately 750 species, notified from different insects. Many of these are proved to be highly potential in pest management. The most considerable fungal species are Metarhizium spp., Beauveria spp., Nomuraea rileyi, Verticillium lecanii and Hirsutella spp., (Alves and Lopes 2008).

There are several bio-pesticides that are commercially available to farmers. A total of 175 registered bio-pesticide active ingredients and 700 products are available, globally, whereas in India so far only 12 bio-pesticides were registered, of which five were bacteria, three fungal, two viruses and two plant products.

Among various bio-products, Bacillus thuringiensis (Bt). Trichoderma viridae, Metarhizium anisopliae, Beauveria bassiana, Nuclear Polyhedrosis Virus (NPV) and neem are popularly used in plant protection (US Environmental Protection Agency, 2007). Hence this study is aimed to evaluate the compatibility of biopesticides including
Streptomyces sp., Metarhizium anisopliae, and neem seed powder against pigeon pea pod borer complex

\section{Materials and Methods}

The findings of the experiment on compatibility of Streptomyces, Metarhizium anisopliae, and neem seed powder against pigeonpea pod borer complex were conducted in the biocontrol laboratory at International crop research institute for the Semi-Arid Tropics (ICRISAT) Patancheru, Hyderabad during 2016-17.

\section{Streptomyces (SAI-25) + Metarhizium anisopliae + Neem seed powder extract using GCY media}

Streptomyces sp. SAI-25 Glucose casaminoacid yeast-extract (GCY) media was used for the dual culture assay. Composition of media was glucose $15 \mathrm{~g}$, Casamino acid $1.5 \mathrm{~g}$, Yeast extract $1.0 \mathrm{~g}, \mathrm{KH} 2 \mathrm{PO} 41.5 \mathrm{~g}, \mathrm{MgSo} 47 \mathrm{H} 2 \mathrm{O}$ $1.0 \mathrm{~g}$ Agar $15 \mathrm{~g}$ and distilled water 1lit. The media was prepared and autoclaved at $121^{\circ} \mathrm{C}$ at $15 \mathrm{lb}$ for $15 \mathrm{~min}$. The autoclaved media was poured into Petri plates in laminar air flow and allowed to cool. A fungal disk (Metarhizium anisipliae) of $6 \mathrm{~mm}$ diameter was placed on one edge (1 cm from the corner) of the GCY agar plate and the SAI-25 was streaked on the other edge of the plate (1 cm from the corner) (Anjaiah et al., 1998) and $100 \mu 1$ and $200 \mu 1$ concentration neem seeds powder extract also adding in each plates. Plates without Streptomyces and Metarhizium anisopliae were used as control. All plates were incubated at $27 \pm 1 \mathrm{oC}$ for until the pathogen completely covered the control plate. Inhibition of fungal mycelium (halo zone) around the Streptomyces sp. colony was noted as positive and the inhibition zone was measured at the end of $24 \mathrm{~h}$ and continued for 5 days, hence compatibility were tested in three replications. 
Streptomyces (SAI-25) + neem seed powder extract using Streptomyces isolation agar media

Streptomyces isolation agar media was used for the dual culture assay. The media was prepared and autoclaved at $121^{\circ} \mathrm{C}$ at $15 \mathrm{lb}$ for $15 \mathrm{~min}$. composition of Actinomycetes Isolation Agar (AIA) media was Sodium caseinate $\quad 2 \mathrm{~g}, \quad$ L-Asparagine $\quad 0.10 \mathrm{~g}$, Dipotassium sulphate $0.50 \mathrm{~g}$, Magnesium sulphate $0.10 \mathrm{~g}$, Ferrous sulphate 0.001g, Agar $15 \mathrm{~g}$ and Distilled water 1 lit.

The autoclaved media was poured into Petri plates in laminar air flow and allowed to cool. SAI-25 was streaked on Streptomyces isolation agar (AIA) and $100 \mu 1$ and $200 \mu 1$ concentration of neem seeds powder extract added in each plate of three replication and observation recorded upto the 5 day. All plates were incubated at $27 \pm 1^{\circ} \mathrm{C}$ for until the pathogen completely covered the control plate.

Metarhizium anisopliae + Neem seed powder extract using Potato dextrose agar media

Potato dextrose agar media used for the dual culture assay. The media was prepared and autoclaved at $121^{\circ} \mathrm{C}$ at $15 \mathrm{lb}$ for $15 \mathrm{~min}$. Composition of Potato Dextrose Agar (PDA) media was Dextrose 20g, Agar $15 \mathrm{~g}$ and Distilled water 1 lit. The autoclaved media was poured into Petri plates in laminar air flow and allowed to cool. A fungal disk (Metarhizium anisipliae) of $6 \mathrm{~mm}$ diameter was placed on one edge $(1 \mathrm{~cm}$ from the corner) of PDA plate and $100 \mu 1$ and $200 \mu 1$ concentration of neem seeds powder extract added in each plate of three replication and observation recorded upto the 5 day. Plates without neem powder concentration were used as control. All plates were incubated at $27 \pm 1^{\circ} \mathrm{C}$ for until the pathogen completely covered the control plate.

\section{Results and Discussion}

The Compatibility of Streptomyces, Metarhizium, and neem seed powder against pod borer complex were conducted in the biocontrol laboratory at International crop research institute for the Semi-Arid Tropics (ICRISAT) Patancheru, Hyderabad during 2016-17.

\section{Compatibility of Streptomyces and Metarhizium anisopliae}

The Compatibility of Streptomyces and Metarhizium anisopliae revealed that a majority of the entomopathogenic fungus, Metarhizium anisopliae isolates, most of them accessioned and available in culture collections, were found compatible with the Streptomyces.

This study shows that the both Streptomyces and Metarhizium anisopliae are compatible and there is no inhibition found during compatibility of both Streptomyces and Metarhizium anisopliae upto the 5 day observations.

The growth phase of the mycelium continuing during compatibility including control (Table 1, Fig. 1).

Compatibility of Streptomyces + metarhizium anisopliae + Neem seed powder

Compatibility was tested in vitro through germination and growth assays. The Compatibility of Streptomyces + metarhizium anisopliae and Neem seed powder experiment was conducted in the In vitro study using dual culture technique with two entomopathogenic organisms and neem seed powder extract of two different concentrations $100 \mu 1$ and $200 \mu 1$. Streptomyces, metarhizium anisopliae and Neem seed powder is being used as a biopesticide for many insect pests. 
Fig.1 Compatibility of Streptomyces and Metarhizium anisopliae

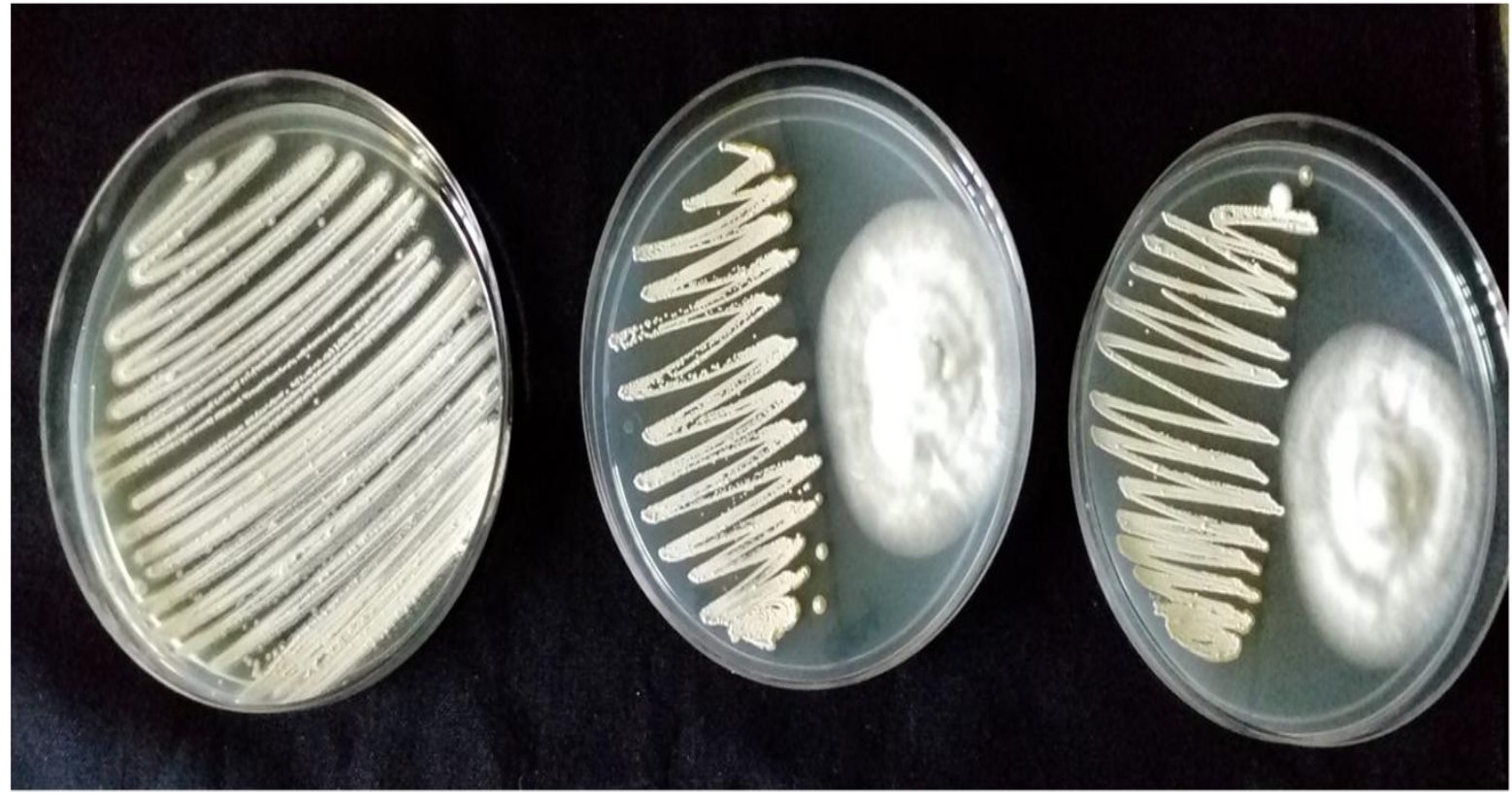

Streptomyces

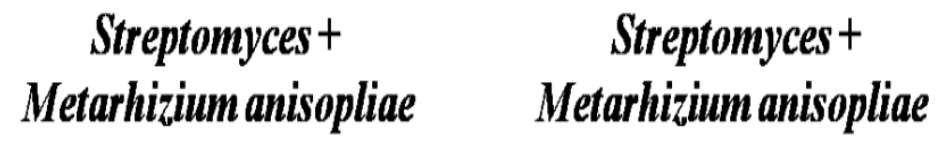

Fig.2 Compatibility of Streptomyces + metarhizium anisopliae + Neem seed powder

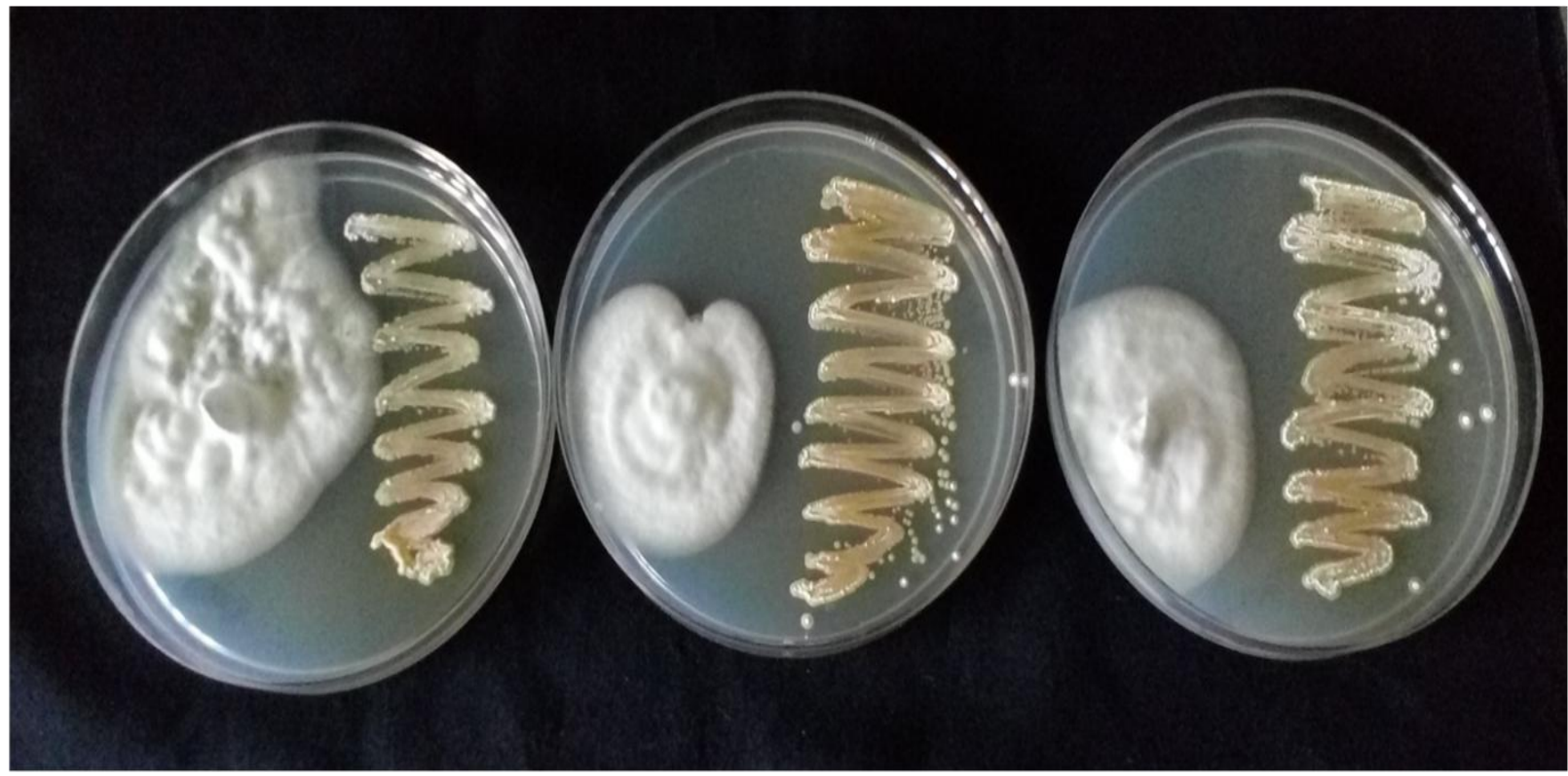

Streptomyces + Metarhizium
Streptomyces + Metarhizium anisopliae + Neem seed powder

$(100 \mu \mathrm{l})$
Streptomyces + Metarhizium anisopliae+Neem seed powder $(200 \mu \mathrm{l})$ 
Fig.3 Compatibility of Metarhizium anisopliae + Neem seed powder

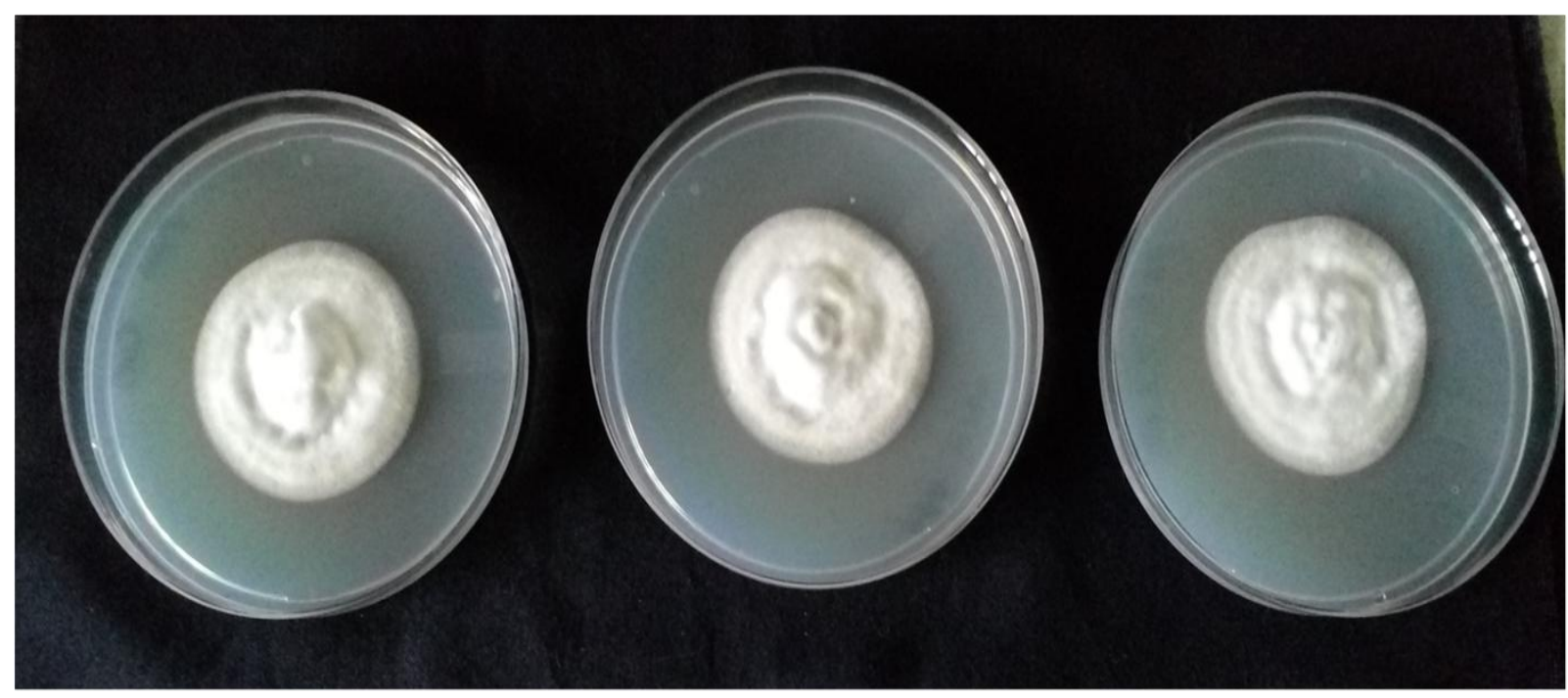

Metarhizium anisopliae

Metarhizium anisopliae Metarhizium anisopliae + Neem + Neem seed powder $(100 \mu \mathrm{l})$ seed powder $(200 \mu \mathrm{l})$

Fig.4 Compatibility of Streptomyces + Neem seed powder

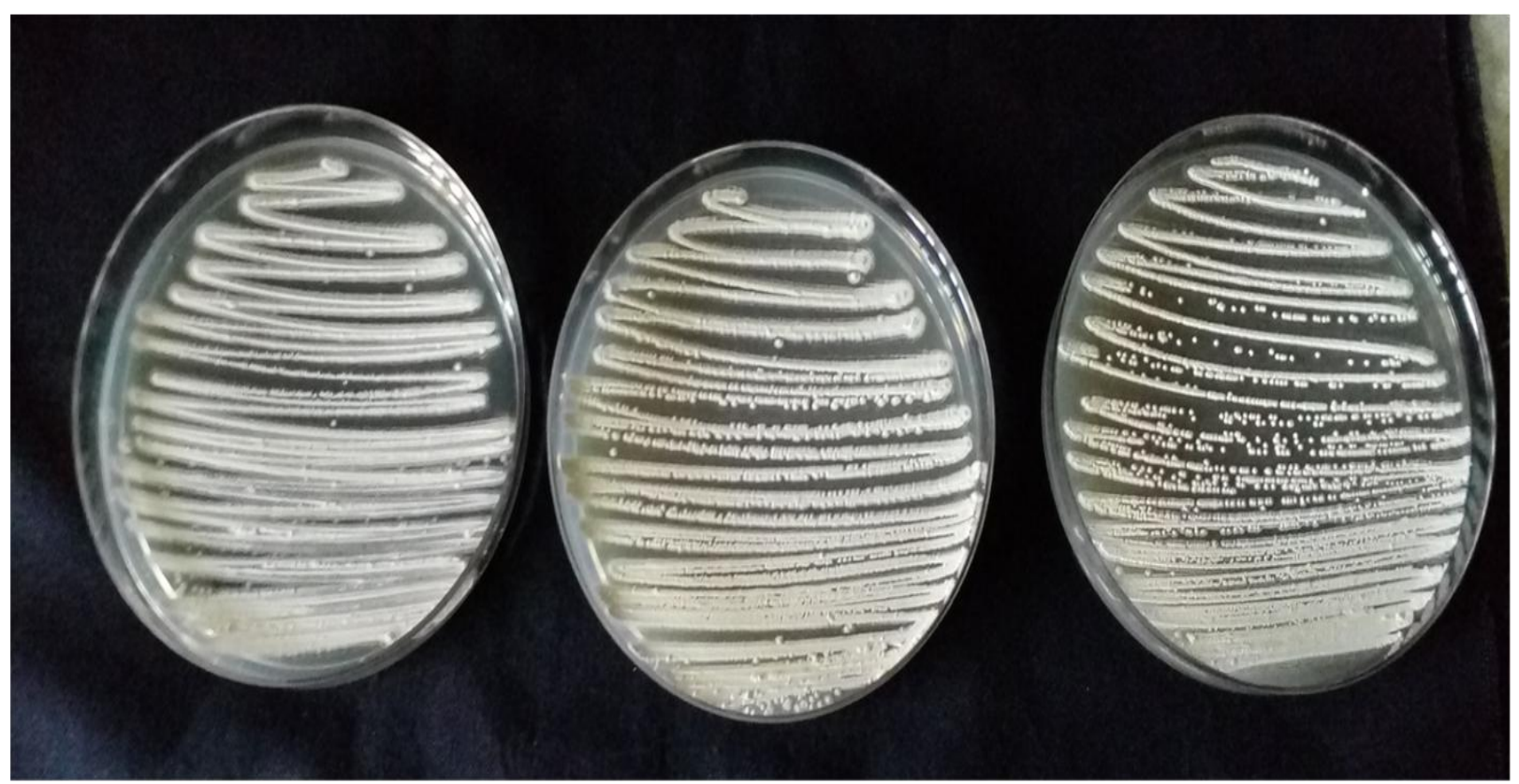

Streptomyces

Streptomyces + Neem seed powder

Streptomyces + Neem seed $(100 \mu l)$ powder $(200 \mu \mathrm{l})$ 
Table.1 Compatibility of different Biopesticides

\begin{tabular}{|c|c|c|}
\hline Sr. No & Treatments & Compatibility \\
\hline 1 & Streptomyces + Metarhizium anisopliae & + \\
\hline 2 & Streptomyces + Metarhizium anisopliae + Neem seed powder $(100 \mu \mathrm{l})$ & + \\
\hline 3 & Streptomyces + Metarhizium anisopliae + Neem seed powder $(200 \mu \mathrm{l})$ & + \\
\hline 4 & Metarhizium anisopliae & + \\
\hline 5 & Metarhizium anisopliae + Neem seed powder $(100 \mu 1)$ & + \\
\hline 6 & Metarhizium anisopliae + Neem seed powder $(200 \mu 1)$ & + \\
\hline 7 & Streptomyces & + \\
\hline 8 & 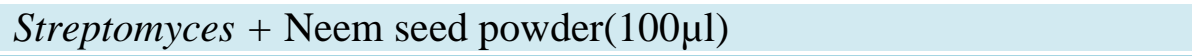 & + \\
\hline 9 & Streptomyces + Neem seed powder $(200 \mu \mathrm{l})$ & + \\
\hline
\end{tabular}

Compatibility studies between Streptomyces + metarhizium anisopliae + Neem seed powder revealed that there was no definite sign of suppression of any of the biopesticides, which significantly compatible growth of compound has been shown. It was concluded the compatibility Streptomyces, metarhizium anisopliae and Neem seed powder was Interestingly and significantly enhanced the growth of all the 3 biopesticides Compatibility. Studies among bacteria and fungus and neem seed powder showed that all were compatible with each other.

The compatibility between the neem derivatives with $M$. anisopliae can be effectively incorporated in the IPM programs for the effective control of pest population. The present findings of Hirose et al., (2001) although the different neem derivatives tested in the present investigations inhibited the growth of $M$. anisopliae in poisoned media in vitro, the combined use of the fungus and neem derivatives cannot be completely ruled out. All the neem derivatives tested in this study have been combined at half recommended dose with entomopathogenic fungi for obtaining better control of pod borer in chickpea considering this, it is worth exploring the effect of these neem derivatives at sublethal dose with fungus for an enhance result over pest control (Table 1, Fig. 2).

\section{Compatibility of Metarhizium anisopliae +} Neem seed powder

Neem seed powder (azadirachtin) is an ecosafe popular botanical pesticide. The Compatibility of Metarhizium anisopliae + Neem seed powder, in order to assess the compatibility of botanical extract i.e., neem seed powder extract was mixed of different concentration $100 \mu 1$ and $200 \mu$ in PDA plates containing selected entomopathogenic microorganism such as Metarhizium anisopliae in three replications. This study revealed that neem seed powder was found to be compatible with fungus Metarhizium anisopliae. There were no signs of suppressing or inhibition appears upto the 5 day. Mohan et al., 2007 reported that Beauveria bassiana is being used as a biopesticide for many insect pests. A biopesticde with a neem compatible isolate of B. bassiana will enable their simultaneous use in pest management. The effect of neem derivatives on the mycelial growth of $M$. anisopliae was conducted in in vitro. All the treatments showed significant mycelial growth, but less than control. Among neem derivatives tested, Neem soap $0.5 \%$ (w/v) (half recommended dose) was found more compatible with least growth inhibition percentage followed by Neem oil $2.5 \%(\mathrm{v} / \mathrm{v})$ and NSKE $2.5 \%(\mathrm{w} / \mathrm{v})$. The present findings 
are in conformity with the findings of Hirose et al., (2001) they also reported that neem oil less than $0.25 \%$ or neem derivatives less than $5 \%$ were relatively less toxic for mycelial growth and spores of $M$. anisopliae. The effect of neem derivatives on the mycelial growth of $M$. anisopliae was conducted in in vitro. All the treatments showed significant mycelial growth, but less than control. Among neem derivatives tested, Neem soap $0.5 \%(\mathrm{w} / \mathrm{v})$ (half recommended dose) was found more compatible with least growth inhibition percentage followed by Neem oil $2.5 \%(\mathrm{v} / \mathrm{v})$ and NSKE $2.5 \%(\mathrm{w} / \mathrm{v})$ (Table 1, Fig. 3).

\section{Compatibility of Streptomyces + Neem seed powder}

Neem seed powder has minimal to no impact on non-target organisms, is compatible with other biological control agents and has a good fit into classical Integrated Pest Management programmes. Compatibility was tested in vitro using dual culture assay of Streptomyces + Neem seed powder, the neem seed powder was used with different concentrations such as $100 \mu 1$ and $200 \mu 1$ this concentration have been mixed with Streptomyces culture separately for the compatibility study. This result revealed that when neem seed powder of two different concentrations mixed with the Streptomyces showing significant growth of Streptomyces and there is no suppression of growth was occurs of Streptomyces up to the 5 day observations. Both Streptomyces + Neem seed powder was showing compatible with each other (Table 1, Fig. 4).

\section{Acknowledgement}

The authors are highly thankful to Dr. Gopalakrishanan subramaniam (Senior scientist), Biocontrol, Division of Crop Protection, at International crop research institute for the Semi-Arid Tropics
(ICRISAT) Patancheru, for providing necessary facilities for carrying out this research work and finally thanks for financial support.

\section{References}

Alves SB and Lopes RB. 2008. Controle microbiano de pragas na América Latina. Avançose desafios. Piracicaba: FEALQ, 414p.

Anjaiah VK, Nowak TB, Loper JE, Hofte M, Tambong JT and Cornelis P. 1998. Involvement of phenazines and anthranilate in the antagonism of Pseudomonas aeruginosa PNAI and Tn5 derivatives towards Fusarium sp. and pythium sp. Mol. Plant Microbe. Interact 11:847-854.

Balikai RA and Yelshetty S. 2008. Insect Pest Scenario of Pigeon pea in Northern Karnataka. Legume Research. 31(2): 120-125.

Enrique Castiglioni, José Djair Vendramim and Sérgio Batista Alves. 2003. Compatibility between Beauveria bassiana and Metarhizium anisopliae with Nimkol-L® in the control of Heterotermes tenuis. Manejo Integrado de Plagas y Agroecología 69:38-44.

FAOSTAT, 2012. Food and Agriculture Organization (FAO): Agriculture production.

Gopalakrishnan S, Watanabe T, Pearse SJ, Hossain ZO and Subbarao GV. 2009. Biological nitrification by Brachiaria humidicola roots varies with soil type and inhibits nitrifying bacteria, but not other major soil microorganisms. Soil Sci. Plant Nutr. 55: 725-733.

Hirose E, Neves OJ, Zequi AC, Martins LH, Peralta $\mathrm{CH}$ and Junior, A. 2001. Effect of biofertilizers and neem oil on the entomopathogenic fungi Beauveria bassiana (Bals.) and Metarhizium anisopliae (Metsch.) Sorok. Brazilian 
Archives of Biology and Technology 44(4):419-423.

José M De Araujo Jr, Edmilson J Marques, José V De Oliveira 2009. Potential of Metarhizium anisopliae and Beauveria bassiana isolates and Neem oil to control the aphid Lipaphis erysimi (Kalt.) (Hemiptera: Aphididae). Neotropical Entomology 38(4):520-525.

Mohan MC, Reddy PN, Devi UK, Kongara R. and Sharma HC. 2007. Growth and insect assays of Beauveria bassiana with neem to test their compatibility and synergism. Biocontrol Science and Technology, 17(10): 1059-1069.

Pandey SA and Das SB. 2016. Evaluation of biopesticides against gram pod borer Helicoverpa armigera (HUB.) on pigeonpea. Legume Research, 39 (3): $479-481$.

Sharma HC, Clement SL, Smith TJ, Ranga Rao GV, Bouhssini M, Ujagir R,
Srivastava CP and Miles M. 2008. Insect pest management in food legumes: The future strategies. In: Forth International. Conference of Food Legumes Research. Indian Society of Genetics and Plant Breeding, New Delhi, India. pp. 522 - 544.

Tabo R, Ezueh MI, Ajayi O, Asiegbu JE and Singh L. 1995. Pigeon pea production and utilization in Nigeria. International Chickpea and Pigeonpea Newsletter 2: 47-49.

US Environmental Protection Agency 2007. Information Published at web site. Info $\{@$ healthgoods.com.

Yelshetty S, Patil BV and Lingappa S. 2003. Evaluation of Integrated Pest Management Modules against Pod Borer, Helicoverpa armigera (Hubner) in Pigeon pea Ecosystem. Karnataka J. Agric. Sci. 16 (1): 54-60.

\section{How to cite this article:}

Agale, S.V., S. Gopalakrishnan, Rajeev Gupta, G.V. Rangarao, V. Srinivas and Wani, S.P. 2018. Compatibility of Streptomyces sp., Metarhizium anisopliae, and Neem Seed Powder against Pigeon Pea Pod Borer Complex. Int.J.Curr.Microbiol.App.Sci. 7(02): 390-397. doi: https://doi.org/10.20546/ijcmas.2018.702.050 